\title{
The Longevity Annuity: An Annuity for Everyone?
}

\author{
Jason S. Scott
}

As of 2005, U.S. individuals had an estimated \$7.4 trillion invested in IRAs and employersponsored retirement accounts. Many retirees will thus face the difficult problem of turning a pool of assets into a stream of retirement income. Purchasing an immediate annuity is a common recommendation for retirees trying to maximize retirement spending. The vast majority of retirees, however, are unwilling to annuitize all their assets. This research demonstrates that a "longevity annuity," which is distinct from an immediate annuity in that payouts begin late in retirement, is optimal for retirees unwilling to fully annuitize. For a typical retiree, allocating 10-15 percent of wealth to a longevity annuity creates spending benefits comparable to an allocation to an immediate annuity of 60 percent or more.

$\mathbf{T}$ he aging of the U.S. population and the demise of the defined-benefit (DB) plan are two major trends reshaping the retirement landscape. As of this writing, the oldest of the Baby Boomers have already turned 60. The aging of that generation will create an unprecedented explosion in the retiree population. The assets available to these new retirees are also undergoing significant change. The past two decades have seen a substantial shift from DB-funded pensions toward a reliance on IRA and 401(k) accounts to fund retirement. As of 2005, Americans had approximately $\$ 7.4$ trillion invested in IRAs and employer-sponsored defined-contribution plans, compared with $\$ 1.9$ trillion in employer-sponsored DB plans (Investment Company Institute 2006). This shift has raised a critical question for many newly minted retirees: "How can I convert accumulated assets into retirement income?"

An immediate annuity is a common recommendation-from practitioners and academics alike-to maximize retirement income from a given pool of assets. In a typical immediate annuity contract, an insurance company promises to make regular monthly or annual payments for the life of the individual in exchange for a one-time premium payment.

Jason S. Scott is managing director of the Retiree Research Center at Financial Engines, Incorporated, Palo Alto, California.

Note: The views expressed herein are those of the author and not necessarily those of Financial Engines.
More than four decades have passed since economic theory first concluded that individuals who wish to maximize guaranteed spending in retirement should convert all their available assets to an immediate annuity (see Yaari 1965). Yet, few retirees allocate any dollars to an immediate annuity, much less fully annuitize. ${ }^{1}$ Given retirees' reluctance to make annuity purchases, I extend the theoretical analysis by considering the question, "Which annuity should I buy with a fraction of my assets?"

The gulf between theory and behavior is so wide that numerous academic studies have analyzed the "annuity puzzle." ${ }^{2}$ An important aspect is that virtually all of the previous analyses assumed that the fundamental annuity contract available is an immediate annuity. However, a new type of annuity contract, a "longevity annuity," has recently been introduced. ${ }^{3}$ Longevity annuities are essentially immediate annuity contracts without the initial payouts. That is, a longevity annuity involves an up-front premium with payouts that begin in the future. For example, an age-85 longevity annuity can be purchased at age 65 with payouts commencing only when and if the purchaser reaches age 85 .

Researchers are starting to consider longevity annuities. Milevsky (2005) assessed the potential for employees to use periodic contributions to their pension plan to purchase longevity annuity payouts. Milevsky identified as barriers to implementation the piecemeal purchase and the potential for a gap in timing between purchase and payouts to exceed 30 years. ${ }^{4} \mathrm{Hu}$ and Scott (2007) demonstrated that longevity annuities are generally preferable to immediate annuities because of the many 
well-documented behavioral biases in decision making. As I will show, longevity annuities not only have a behavioral advantage, but they also have a purely rational advantage. In particular, longevity annuities maximize the insurance benefit per premium dollar. For that reason, longevity annuities, especially those that start payouts late in life, may indeed qualify as an annuity for everyone.

\section{What Makes Insurance Valuable?}

Before diving into the issue of longevity risk and annuities, I start with a basic question: What makes insurance valuable? First, consider the answer in a simple setting. Suppose a driving enthusiast absolutely must have a car. Furthermore, suppose this driver has no access to insurance to replace the car if an accident occurs. To self-insure, he must set aside enough money for a replacement car in case of an accident. The money he sets aside he cannot spend.

Access to car insurance completely changes the situation. Now, the motorist has to set aside only the cost of insurance. Any remaining dollars he can now safely spend on other things. The size of this windfall to the driver depends crucially on the insurance cost relative to the replacement cost. (Throughout this example, all claims are assumed to be for the full value of the car.) For example, assume the car has a replacement cost of $\$ 20,000$. Suppose the driver has an excellent driving record and only a 5 percent chance of making an insurance claim. If insurance is sold at cost, then the car insurance price is $\$ 1,000 .^{5} \mathrm{In}$ this case, purchasing insurance allows the driver $\$ 19,000$ in additional spending relative to self-insurance. So, at this price, the insurance provides $\$ 19$ of additional spending per $\$ 1$ of insurance premium.

If the driver has a history of wrecking cars, the chance of totaling the car is now much higher, so the price for car insurance also rises. Suppose the chance of an accident has increased fivefold, to 25 percent. The cost of insurance also rises fivefold, to $\$ 5,000$. Now, purchasing insurance allows only $\$ 15,000$ in additional spending. The spending improvement per premium dollar has been reduced to just $\$ 3$. Although insurance still makes sense, the benefit relative to self-insurance is less compelling.

In the extreme case of a reckless driver with a 95 percent chance of totaling the car, the insurance cost may rise to a staggering $\$ 19,000$. The spending benefit per premium dollar has shrunk to a paltry 5 cents. If the insurance price is cost plus a profit premium, it could actually exceed the replacement cost for this driver.

Analyzing the spending improvement per premium dollar helps individuals select from compet- ing insurance contracts. Suppose an individual has an additional dollar she is willing to allocate to insurance. What insurance contract should she select? When the alternative is self-insurance, the answer is simple. She should allocate the extra insurance dollar to the insurance contract that frees up the most spending. In other words, she should select the insurance product with the highest spending improvement per premium dollar. To simplify the exposition, I refer to this quantity as the "spending improvement quotient," or $Q$. Specifically,

$$
\begin{aligned}
Q & =\text { Spending improvement quotient } \\
& =\frac{\text { Self-insurance costs }- \text { Insurance costs }}{\text { Insurance costs }} .
\end{aligned}
$$

In the car insurance examples, the insurance cost was simply the car replacement cost reduced to reflect the chance of an insurance payout. If the probability of an insurance payout is denoted by $P$, then the spending improvement quotient simplifies to:

$$
\begin{aligned}
Q & =\frac{\text { Self-insurance costs }-(P \times \text { Self-insurance costs })}{P \times \text { Self-insurance costs }} \\
& =\frac{1-P}{P} .
\end{aligned}
$$

This result is intuitive. To evaluate the potential insurance benefit, one simply considers the likelihood of a payout. If an insurance payout is unlikely, insurance is generally cheap relative to self-insurance and insurance can provide substantial benefits. If an insurance payout is highly likely, insurance cannot be provided at much of a discount to self-insurance. In such conditions, insurance provides little benefit.

These fundamental concepts apply to all insurance contracts, including longevity insurance. Focusing on high-value, or high- $Q$, insurance is the key to maximizing the benefit per premium dollar. ${ }^{6}$

\section{Turning IRAs into Income}

With the dramatic increases in IRA and 401(k) plan balances, a common problem facing retirees will be turning those assets into income. To illustrate how insurance concepts apply to the retirement income problem, I analyze the problem faced by a newly retired individual. This retiree is 65 years old and has a \$1 million IRA available to fund retirement spending.

Before tackling the full retirement problem, consider the simpler problem of funding spending for a single year 20 years in the future. For the retiree, this would correspond to funding spending at age 85. If the retiree wants a guaranteed payout in 20 years time, an obvious investment choice is a zerocoupon bond. The price today for a bond that pays 
$\$ 1$ in 20 years, $B_{20}$, depends on the prevailing interest rates. Assuming interest rates are 2.5 percent at all maturities, spending in 20 years will cost: ${ }^{7}$

$$
\begin{aligned}
B_{20} & =\begin{array}{l}
\text { Price today of a zero-coupon bond } \\
\text { paying out } \$ 1 \text { in } 20 \text { years }
\end{array} \\
& =\frac{1}{(1.025)^{20}} \\
& =\$ 0.61 .
\end{aligned}
$$

Each dollar the retiree wants to spend at age 85 can be initially secured for a 61 cent investment in a 20-year zero-coupon bond.

Securing spending with bonds is analogous to setting aside the full replacement cost of the car. With self-insurance, the money is set aside whether or not the insurance event occurs. Similarly, the dollar from the zero-coupon bond is available whether or not the retiree actually lives to spend it.

An alternative to using bonds is an annuity contract. Suppose the retiree can purchase an annuity contract today that has a one-time payout in 20 years. The annuity contract differs from the bond in that the payout is contingent on survival. Given the similarities in payout structure, I will call this single-payment annuity a "zero-coupon annuity."

How much does a $\$ 1$ payout in 20 years cost when using a zero-coupon annuity? As in the car insurance example, the price for longevity insurance depends on the probability of a payout. For longevity insurance, the payout probability is the chance of the retiree surviving 20 years to qualify for the payout. If $S_{20}$ is the 20-year survival probability, then the zero-coupon annuity price, $A_{20}$, is

$$
\begin{aligned}
A_{20}= & \text { Price today of a zero-coupon annuity } \\
& \text { paying } \$ 1 \text { in } 20 \text { years, if alive } \\
= & S_{20} \times B_{20} .
\end{aligned}
$$

If the retiree is male, the 20-year survival probability appropriate for annuity pricing is about 52 percent. 8 Even with some insurance marketrelated frictions, a zero-coupon annuity offers spending in 20 years at nearly a 50 percent discount to self-insurance in the bond market.

As in the car insurance example, a spending improvement quotient for the 20-year zero-coupon annuity can be calculated. In this case, the $Q$ is

$$
\begin{aligned}
Q_{20} & =\frac{\text { Self-insurance costs }- \text { Insurance costs }}{\text { Insurance costs }} \\
& =\frac{B_{20}-A_{20}}{A_{20}} \\
& =\frac{1-S_{20}}{S_{20}} \\
& =0.94 .
\end{aligned}
$$

That is, the future spending that costs $\$ 1.94$ to secure in the bond market costs only $\$ 1.00$ in the annuity market. Thus, every annuity dollar allocated to finance spending at age 85 frees up 94 cents for additional spending.

The preceding analysis indicates that annuitybased spending at age 85 can be secured at a substantial discount to bond-based spending. The same analysis applies to spending each year throughout retirement. Figure 1 displays the results from repeating the $Q$-analysis for each age between 65 and 100 . The range of spending improvements is surprising. The potential insurance benefit for spending at age 66 is a paltry 1 cent per premium dollar. Given the previous examples, the reason for this result is obvious. People who purchase annuities at age 65 almost always live to collect the payment at age 66. In this situation, potential insurance benefits are extremely limited. In contrast, the age-100 payment has a $Q$-value of 31.79 . Funding spending at age 100 with an annuity costs only pennies on the dollar compared with the cost of a bond. For this individual, the insurance benefit of the age-100 zero-coupon annuity is approximately 2,500 times the insurance benefit provided by the age-66 zero-coupon annuity.

Abstracting from the details of Figure 1, the message is clear. Longevity insurance provides substantial benefits for late-life spending but much smaller benefits for near-term spending. ${ }^{9}$ This observation explains both the problem with immediate annuities and the potential of longevity annuities. Both immediate and longevity annuities can be thought of as bundles of zero-coupon annuities. An age-85 longevity annuity, for example, bundles together each of the zero-coupon annuities from age 85 onward. Similarly, immediate annuities represent a bundle of all the zero-coupon annuities. The difference between the two types of annuities is that immediate annuities add nearterm, low-value annuity payments to the bundle. The resulting blended average $Q$-value for the immediate annuity is 0.56 .10 In contrast, the $Q$-value for the age-85 longevity annuity, at 2.93, is more than five times higher.

\section{Longevity Annuities to Maximize Spending}

For each dollar the retiree shifts from bonds to immediate annuities, 56 cents is available for additional spending. If all assets were shifted to an immediate annuity, spending would increase by 56 percent relative to a bond-based spending program.

But what if the retiree is uncomfortable with a 100 percent allocation to annuities? How should 
Figure 1. Spending Improvement Quotient, Q: Zero-Coupon Annuity Payment

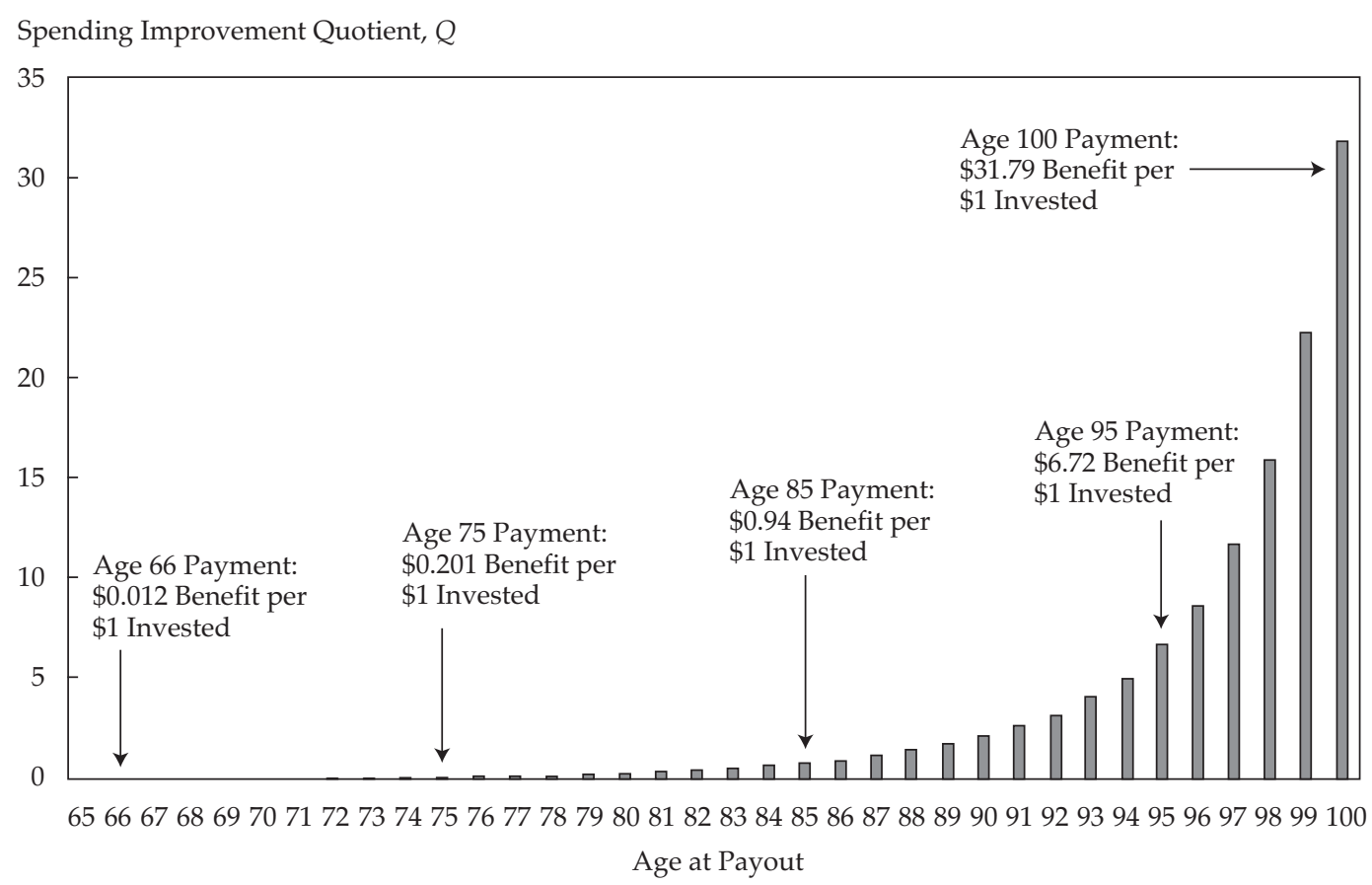

retirees allocate the dollars they are willing to annuitize? Figure 1 provides the basis for an answer. For the first dollar annuitized, the best spending improvement can be had by purchasing the age- 100 zero-coupon annuity. Indeed, putting all annuity wealth into the age-100 annuity is tempting. After all, look at the spending boost! The retiree needs spending in every year, however, not just at age 100. Even though he cannot focus all spending on age100 annuities, the first bonds that should be substituted with annuities should be bonds earmarked for age-100 spending. Assuming the retiree wishes to allocate more dollars to annuities, the next-highest surplus-producing annuity will be the age-99 annuity followed by the age- 98 annuity.

The optimal bundle of zero-coupon annuities to purchase thus depends on the amount of assets the retiree is willing to annuitize. Notice that all optimal bundles are longevity annuities because optimal strategies entail sequentially adding earlier and earlier zero-coupon annuities. If he is willing to annuitize only a few dollars, then the longevity annuity that begins payments at age 100 is optimal. If more dollars are available for annuitization, a longevity annuity that begins payouts at age 99 is in order. The start age for the longevity annuity payments will continue to be reduced until the annuity allocation is exhausted. Surprisingly, only retirees interested in fully annuitizing their assets should select an immediate annuity. All other retirees should opt for the longevity annuity that exhausts their willingness to annuitize. ${ }^{11}$

Figure 2 illustrates the difference between allocating dollars to immediate annuities and allocating dollars to longevity annuities. Allocations to immediate annuities result in a constant 56 cents additional spending per dollar annuitized. Thus, the available spending when an immediate annuity is used increases linearly from a base of $\$ 41,416$ with a pure bond portfolio to a maximum of $\$ 64,645$ with a 100 percent annuity allocation. The curve corresponds to the spending achievable with longevity annuities. The longevity annuity's curvature stems from the fact that the initial dollars are spent on high- $Q$, age-100 payments. Additional dollars are then spent on successively lower- $Q$ payments. Diminishing returns cause the slope of the longevity annuity curve to gradually flatten as the annuity allocation increases.

The longevity annuity's spending curve shares both the beginning and ending points with the immediate annuity spending line. The two strategies emanate from the same point because 0 percent annuitized corresponds to bond-only income for both. With 100 percent annuitized, a longevity annuity has a payment start date that is immediate. Thus, the two annuity options also share the 100 percent annuitized point. At every point between 0 percent and 100 percent annuitized, however, the longevity annuity provides higher spending levels per dollar annuitized. 
Figure 2. Longevity Annuity Spending vs. Immediate Annuity Spending

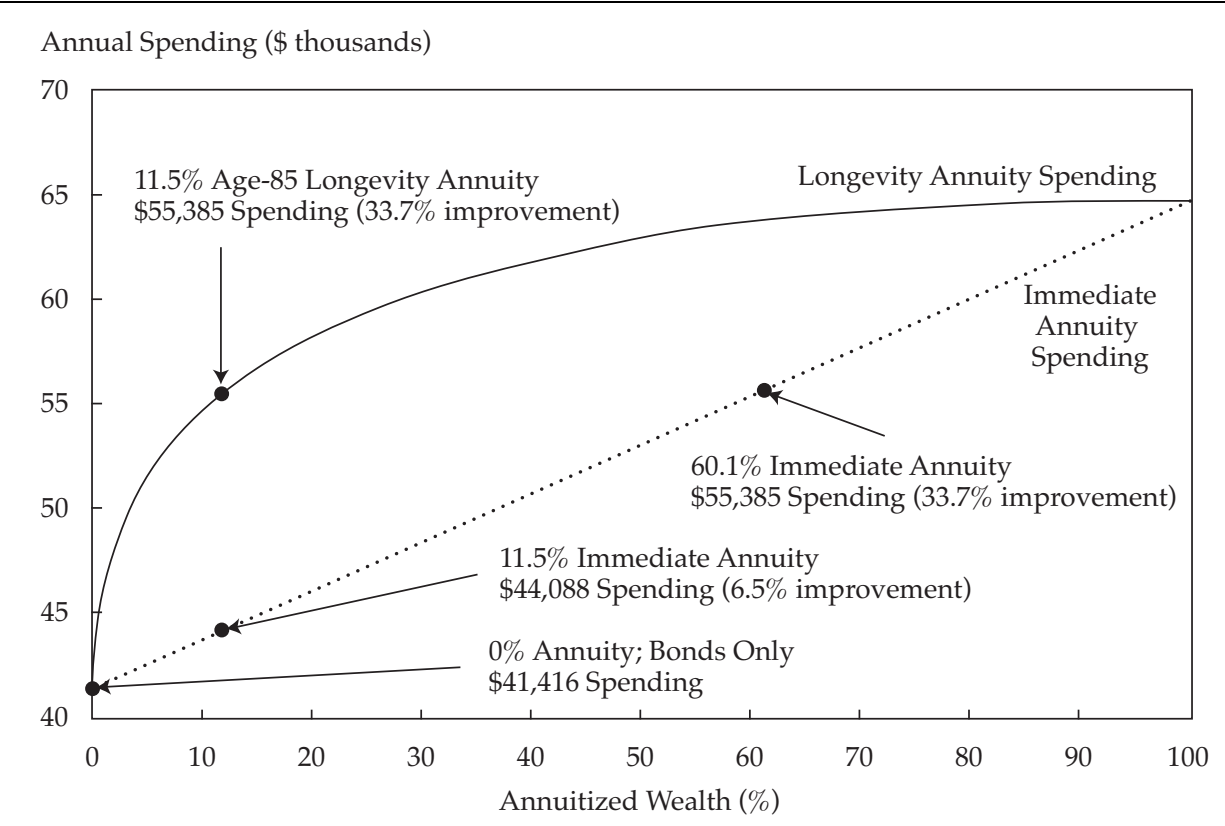

Note: $\$ 1$ million in assets, age 65 , male.

To grasp the leverage available from longevity annuities, consider the age- 85 longevity annuity (i.e., the longevity annuity that begins to make payments at age 85$).{ }^{12}$ Suppose the retiree with the $\$ 1$ million funds spending prior to age 85 with bonds and funds spending after age 85 with a longevity annuity. Using the bond and annuity prices derived previously, he finds that an 11.5 percent allocation to an age-85 longevity annuity will generate annual payouts of $\$ 55,385$ starting at age 85. Allocating the balance of the portfolio to zerocoupon bonds generates $\$ 55,385$ in annual income prior to age 85 . Thus, this combination has increased annual spending throughout retirement by 33.7 percent relative to using a bond-only portfolio.

If an immediate annuity were used instead, the same 11.5 percent annuity allocation would increase spending only by 6.5 percent. To achieve a comparable spending increase with immediate annuities, the retiree would have to allocate more than 60 percent of his portfolio to annuity purchases. Convincing a retiree to annuitize 60 percent of assets would be extremely challenging irrespective of the potential benefit. Annuitizing 11.5 percent of assets might prove much more palatable, especially if this modest allocation allowed guaranteed spending to increase by more than a third. The ability of longevity annuities to deliver a majority of the annuitization benefits for a relatively small portfolio allocation makes them a powerful tool to help retirees effectively turn assets into income.

\section{Robustness Analysis}

The preceding analysis made three key assumptions to allow evaluation of the relative efficiency of longevity annuities. Those assumptions were the mortality rates for retirees, the prevailing interest rates for bond investments, and the formula by which insurance companies turn mortality and interest rates into annuity prices. This section explores the impact of altering these key assumptions.

The robustness analysis consists of analyzing six cases, each with a different set of core assumptions. The results for each case are reported in Table 1.

Case 1 assumes the retiree is male, prevailing interest rates are 2.5 percent, and annuity prices are determined by using the theoretical model described in the preceding paragraphs. Thus, Case 1 corresponds to the situation previously explored in detail. Given those assumptions, an 11.5 percent allocation to an age- 85 longevity annuity provides more than five times the spending improvement of the immediate annuity ( 33.7 percent vs. 6.5 percent).

In Case 1, the retiree was assumed to be a man. Women, however, have different mortality rates. Given that mortality plays a critical role in annuity pricing, Case 2 repeats the analysis for a female retiree. An improved mortality rate has increased the annuity costs in general, but longevity annuities still provide substantial benefits relative to immediate annuities. For this retiree, the spending increase with a longevity annuity is 4.35 times as big as with an immediate annuity. 
Table 1. Robustness Analysis: Interest Rate, Mortality, and Annuity Pricing Assumptions for Age-85 Longevity Annuity vs. Immediate Annuity

\begin{tabular}{|c|c|c|c|c|c|c|}
\hline & \multicolumn{4}{|c|}{ Theoretical Bond/Annuity Prices } & \multicolumn{2}{|c|}{$\begin{array}{l}\text { Actual Bond/ } \\
\text { Annuity Prices }\end{array}$} \\
\hline & Case 1 & Case 2 & Case 3 & Case 4 & Case 5 & Case 6 \\
\hline \multicolumn{7}{|l|}{ Assumption } \\
\hline Mortality: male (M) vs. female (F) & M & $\mathrm{F}$ & M & $\mathrm{F}$ & M & $\mathrm{F}$ \\
\hline Interest rates: real $2.5 \%$ rate vs. nominal $5 \%$ rate $(\%)$ & 2.5 & 2.5 & 5.0 & 5.0 & $\sim 5.0^{\mathrm{a}}$ & $\sim 5.0^{\mathrm{a}}$ \\
\hline Bond-only spending from $\$ 1$ million (\$) & 41,416 & 41,416 & 57,557 & 57,557 & 58,841 & $\$ 58,841$ \\
\hline \multicolumn{7}{|l|}{ Age-85 longevity annuity results } \\
\hline Optimal annuity allocation $(\%)^{b}$ & 11.5 & 15.3 & 8.2 & 10.9 & 7.9 & 10.4 \\
\hline Spending improvement (\%) & 33.7 & 27.9 & 21.9 & 18.3 & 21.5 & 18.2 \\
\hline \multicolumn{7}{|l|}{ Immediate annuity results ${ }^{\mathrm{c}}$} \\
\hline Annuity allocation (\%) & 11.5 & 15.3 & 8.2 & 10.9 & 7.9 & 10.4 \\
\hline Spending improvement (\%) & 6.5 & 6.4 & 3.3 & 3.3 & 3.1 & 3.1 \\
\hline Longevity annuity benefit multiple $\mathrm{d}^{\mathrm{d}}$ & 5.23 & 4.35 & 6.61 & 5.52 & 6.91 & 5.84 \\
\hline
\end{tabular}

Case 1 and Case 2 assume an interest rate of 2.50 percent. As of this writing, this interest rate corresponds to the real rate of interest available from government inflation-indexed bonds. If the dollars the retiree is trying to secure each year in retirement are inflation-indexed dollars, then this real interest rate is appropriate for the calculations. Some retirees, however, may opt for fixed spending that does not increase with inflation. For this situation, using nominal interest rates in the calculations is appropriate. As of this writing, nominal interest rates are approximately 5.00 percent. Case 3 and Case 4 thus repeat the analysis using the nominal rate of interest. Although the specific numbers have changed, the relative strength of longevity annuities remains. ${ }^{13}$ For these cases, the spending improvement for the longevity annuity relative to the immediate annuity increases by a factor of 6.61 for a male retiree and 5.52 for a female retiree.

The analysis up to this point has been somewhat theoretical to help pinpoint the key reasons longevity annuities provide substantial advantages. An important point, however, is that benefits from longevity annuities can be readily achieved by retirees in the real world. As of this writing, at least three insurance companies are offering longevity annuities. Metropolitan Life Insurance Company (MetLife) introduced longevity annuities in 2004 under the product name Retirement Income Insurance. In March 2006, The Hartford Financial Service Group introduced a longevity annuity product named The Hartford Income Security. Presidential Life Insurance Company also offers a longevity annuity product. Although all of the products provide a straightforward way of securing fixed nominal payouts in retirement, none offers the ability to generate inflation-protected payouts. ${ }^{14}$ Theoretical versus actual pricing comparisons can thus be made only for annuities with fixed nominal payouts.

Actual bond and annuity prices can be obtained to assess the validity of the preceding analysis in the real world. In July 2006, MetLife provided a longevity annuity price quote for a 65-year-old wishing to purchase an age-85 longevity annuity. ${ }^{15}$ In addition to annuity prices, bond yields are required to perform this analysis. U.S. Treasury yield data were obtained on 13 July 2006. At that time, the yield curve for government securities ranged from 5 percent to 5.27 percent.

Case 5 and Case 6 report the results when actual bond and annuity prices were used. For a male retiree, a modest 7.9 percent longevity annuity allocation allows spending to increase by 21.5 percent. A comparable allocation to an immediate annuity increases spending only by 3.1 percent. For this real-world case, the spending improvement from longevity annuities is 6.91 times the spending improvement achieved from immediate annuities.

The results from using actual prices are comparable to those achieved with theoretical pricing assumptions (Case 3 and Case 4). If anything, actual prices suggest that the size of the longevity annuity advantage is slightly underestimated in the theoretical pricing model. 
Although actual prices confirm the longevity annuity advantage over an immediate annuity, note that neither annuity has met with large-scale economic success. So, whether recently introduced longevity annuities will ultimately increase the popularity of annuities or will result in yet another annuity puzzle remains to be seen. ${ }^{16}$

This robustness analysis has considered the influence of three critical assumptions: mortality rates, interest rates, and annuity pricing formulas. Although the particulars of the analysis do indeed depend on these three factors, the advantage of longevity annuities was robust across all of these permutations. In some sense, the robustness is not surprising. The key to longevity annuity benefits is the realization that purchasing income conditional on survival must get cheaper as the chance of survival declines. Because cheaper insurance corresponds to more valuable insurance, longevity annuities allow retirees to concentrate their annuity dollars on high-value insurance. This fundamental advantage of longevity annuities should be robust across virtually all scenarios.

\section{Conclusion}

Millions of retirees will face the problem of translating their accumulated assets into retirement income. Retirees hoping to increase their retirement spending are often counseled, by academics and practitioners alike, to consider immediate annuities. Unfortunately, the theoretical foundation for an immediate annuity relies on the willingness of the retiree to fully annuitize. In practice, virtually no retirees voluntarily annuitize their entire portfolios. This article has extended the theory by answering the key question of which annuity to buy with a portion of one's assets.

The answer to this question is somewhat surprising. By focusing on the fundamental properties that make insurance valuable, I have demonstrated that longevity annuities maximize guaranteed retirement spending per dollar annuitized. Retirees willing to annuitize only a portion of their assets should prefer some form of longevity annuity. In fact, the first few dollars annuitized with a longevity annuity provide such substantial benefits that many retirees should find these annuities desirable. A sample calculation, with actual annuity prices, found that a 65-year-old male retiree could increase his guaranteed spending by more than 21 percent by allocating less than 8 percent of his portfolio to an age-85 longevity annuity. This spending improvement was almost seven times the spending improvement from a comparable immediate annuity allocation.
So, the answer to the question, Is the longevity annuity an annuity for everyone? is a qualified yes. The qualifications stem from the many individualspecific considerations, such as a retiree's wealth, health, and desire to leave a bequest, that are important to the annuitization decision. For example, a retiree without liquid wealth is clearly a poor candidate for a longevity annuity purchase. ${ }^{17}$ In addition, a wealth level probably exists that is so high that spending and longevity considerations are irrelevant. For retirees with wealth levels between these extremes, however, longevity annuities can play an important role in maximizing retirement spending. Similar caveats apply to retirees in poor health. A retiree with no prospect of surviving beyond age 85 should not be interested in a longevity annuity. A retiree with assets set aside to support post- 85 spending will find, however, that a longevity annuity provides comparable spending at a lower cost irrespective of their current health level. Finally, the desire to leave behind an estate may motivate some retirees to avoid annuities. However, because the longevity annuity outlay typically absorbs only $10-20$ percent of assets, the bequest motive would have to be powerful indeed to eliminate all demand for longevity annuities. Therefore, qualifications to the yes answer are certainly in order, but they appear to be more the exception than the rule. In fact, as Baby Boomers increasingly enter retirement with a 401(k) balance rather than a corporate income promise, this analysis suggests that most will find that a modest longevity annuity purchase can substantially increase their spending in retirement.

I would like to thank Wei-Yin Hu, David Ramirez, Andrea Scott, and John Watson for many excellent comments and suggestions.

This article qualifies for 1 CE credit.

\section{Appendix A. Public Policy Considerations}

A straightforward economic analysis demonstrates the desirability of longevity annuities. Large-scale adoption of longevity annuities may depend critically, however, on public policy decisions. Two important policy issues that could increase the use of longevity annuities are the current rules regarding minimum required distributions and the inclusion of a longevity annuity option in employer-sponsored plans. 
First, the current IRS rules regarding minimum required distributions (MRDs) create a barrier to the adoption of longevity annuities. Annuities that begin payouts after age 70 currently run afoul of the MRD rules. For example, an age- 65 retiree who uses his IRA to purchase an age- 85 longevity annuity cannot make the MRD at age 70 because no annuity payments are scheduled until age 85 . Even if only a portion of the IRA is used to make the longevity annuity purchase, future market declines or withdrawals can still result in insufficient funds to make the MRD. Recognizing this issue, insurance companies do not currently allow longevity annuities with late-life start dates to be purchased with IRA or 401(k) assets. ${ }^{18}$ Requiring that IRA and 401(k) dollars be distributed and taxed prior to a late-dated longevity annuity purchase creates a substantial barrier to longevity annuity utilization.

The second policy issue relates to the significant role inertia plays in the effectiveness of corporate pension plans. Numerous studies have documented that many employees follow the path of least resis- tance when making decisions regarding their corporate pension. The Pension Protection Act of 2006 (PPA) is landmark legislation in that it encourages employers to "automate" their pension plans with reasonable defaults so that the path of least resistance is likely to lead to a prosperous retirement. Examples of newly made default decisions include automatic enrollment, automatic savings escalations, and automatic portfolio management. Thus, an employee who fails to make any proactive decision is automatically enrolled in the pension plan, contributes at a reasonable level, and is invested in a reasonably diversified portfolio. The PPA was silent, however, on ways to automate the translation of pension assets into income.

Because the benefit per dollar annuitized is dramatic, at least for the late-dated longevity annuities, a longevity annuity with a sufficiently late start date might be an ideal default candidate to help automate the income phase of retirement. The cost might be as little as 5-15 percent of assets, but the longevity protection benefit would be substantial.

\section{Notes}

1. For example, LIMRA International (2007) estimated sales of fixed immediate annuities to be $\$ 5.9$ billion for 2006 .

2. See Brown and Warshawsky (2004) for a summary of explanations for the annuity puzzle, which included a bequest motive, the influence of Social Security, annuity pricing, and irreversibility of the annuity purchase. The full-annuitization prediction is robust, however, to most of these explanations.

3. Longevity annuities are also referred to as "delayed payout" annuities because in them, the annuity payments are delayed relative to an immediate annuity.

4. These two concerns can be mitigated by a longevity annuity lump-sum purchase at retirement. Milevsky also identified as potential problems payout gaps in excess of 10 years for inflation-protected products and the lack of a death benefit. Although inflation protection is not a feature of currently available longevity annuities, these products do allow individuals to select a "no death benefit" option.

5. If the insurance company sells a similar policy to numerous drivers with comparable risk profiles, the average cost of a policy will equal $\$ 20,000 \times 0.05$, or $\$ 1,000$.

6. Note that an expected utility analysis is a more general approach to evaluating insurance options. Using $Q$ simplifies the analysis by assuming that an individual's response is independent of the insurance purchase (e.g., when a crash happens, the same outlay occurs irrespective of whether the individual self-insured or purchased insurance).

7. This interest rate roughly corresponds to the real rate of interest as of this writing.

8. Social Security population average mortality tables indicate a 40 percent survival probability. Survival based on the GAR-94 mortality tables (with generational adjustments) is 51.58 percent. The annuity-pricing survival rate is higher than the average mortality rate for two reasons. First, annuity purchasers are generally healthier than average. Second, insurance companies have to cover the cost of doing business. Given the reserves and adjustments built into the GAR-94 tables, they should be a reasonable choice for estimating annuity prices.

9. This general result is independent of the desired spending pattern (e.g., fixed real, fixed nominal, increasing, decreasing, etc.). Irrespective of the pattern, annuitized wealth optimally supports late-retirement spending whereas nonannuitized wealth should be directed at early retirement spending. See Scott, Watson, and $\mathrm{Hu}$ (2007) for a detailed discussion of this result.

10. The $Q$-value for an immediate annuity can be calculated by comparing a bundle of zero-coupon bonds with a bundle of zero-coupon annuities. Using bonds to purchase $\$ 1$ of spending each year in retirement costs $B_{0}+B_{1}+\ldots+B_{35}=$ $\$ 1+\$ 0.976+\ldots+\$ 0.421=\$ 24.145$. Using annuities to purchase $\$ 1$ of spending each year in retirement costs $A_{0}+$ $A_{1}+\ldots+A_{35}=\$ 1+\$ 0.9636+\ldots+\$ 0.0129=\$ 15.469$. The spending improvement achieved by shifting bond-based to annuity-based spending is thus 0.56 .

11. Interested readers can refer to Scott et al. (2007) for more details on optimal annuitization.

12. This longevity annuity is highlighted because it is the longevity annuity with the latest starting age that is readily available in the market.

13. Fixed nominal payments imply that the retiree is spending more during early retirement and less during late retirement. Because less wealth is used to fund spending after age 85 , the amount optimally allocated to an age- 85 annuity decreases.

14. Some products do allow the retiree to select a payout option that includes fixed annual payout increases once benefits begin. Although not perfectly hedging inflation, this option allows a retiree to prepare for some degree of average anticipated inflation.

15. For a male retiree, a $\$ 100,000$ premium purchased monthly payments of $\$ 7,730$ starting at age 85 , which implies that 
each dollar of annual income starting at age 85 costs approximately $\$ 1.10$ (assuming no within-year mortality and 5 percent interest rates). An age-67 longevity annuity price quote implied a per dollar annuity cost of $\$ 10.24$. The price per dollar spending when an immediate annuity was used was estimated by taking the age- 67 longevity annuity and adding $\$ 1$ and $\$ 0.94$ to account for, respectively, the age- 65 and the age- 66 payments.
16. Public policy changes that would encourage the use of longevity annuities are explored in Appendix A.

17. The potentially perverse incentives associated with Medicaid assistance may cause retirees with little wealth to prefer immediate consumption over longevity insurance.

18. More generally, any assets subject to MRDs are precluded from purchasing a longevity annuity which initiates payouts after age 70 .

\section{References}

Brown, J.R., and M.J. Warshawsky. 2004. "Longevity-Insured Retirement Distributions from Pension Plans: Market and Regulatory Issues." In Public Policies and Private Pensions. Edited by W.G. Gale, J.B. Shoven, and M.J. Warshawsky. Washington, DC: Brookings Institution Press.

Hu, W., and J.S. Scott. 2007. "Behavioral Obstacles in the Annuity Market." Financial Analysts Journal, vol. 63, no. 6 (November/December):71-82.

Investment Company Institute. 2006. "The U.S. Retirement Market, 2005." Research Fundamentals, vol. 15, no. 5 (July): www.ici.org/pdf/fm-v15n5.pdf.
LIMRA International. 2007. "LIMRA Reports Record Sales for U.S. Individual Annuities." Press release (21 March): www.limra.com/Pressroom/PressReleases/pr032107.aspx.

Milevsky, M.A. 2005. "Real Longevity Insurance with a Deductible: Introduction to Advanced-Life Delayed Annuities (ALDA)." North American Actuarial Journal, vol. 9, no. 4 (October):109-122.

Scott, J.S., J.G. Watson, and W. Hu. 2007. "Efficient Annuitization: Optimal Strategies for Hedging Mortality Risk." Pension Research Council Working Paper 2007-9.

Yaari, M.E. 1965. “Uncertain Lifetime, Life Insurance, and the Theory of the Consumer." Review of Economic Studies, vol. 32, no. 2 (April):137-150.

\section{[ADVERTISEMENT]}

